\title{
New Evidence of Neuroprotection by Lactate after Transient Focal Cerebral Ischaemia: Extended Benefit after Intracerebroventricular Injection and Efficacy of Intravenous Administration
}

\author{
Carole Berthet $^{\mathrm{a}}$ Ximena Castillo $^{\mathrm{a}}$ Pierre J. Magistretti ${ }^{\mathrm{b}, \mathrm{c}}$ Lorenz Hirt ${ }^{\mathrm{a}}$ \\ Departments of a Clinical Neurosciences and ${ }^{b}$ Psychiatric Neurosciences, Lausanne University Hospital, and \\ 'Brain and Mind Institute, EPFL, Lausanne, Switzerland
}

\section{Key Words}

Lactate $\cdot$ Cerebral ischaemia $\cdot$ Stroke $\cdot$ Neuroprotection .

Translational research $\cdot$ Middle cerebral artery occlusion

\begin{abstract}
Background: Lactate protects mice against the ischaemic damage resulting from transient middle cerebral artery occlusion (MCAO) when administered intracerebroventricularly at reperfusion, yielding smaller lesion sizes and a better neurological outcome $48 \mathrm{~h}$ after ischaemia. We have now tested whether the beneficial effect of lactate is long-lasting and if lactate can be administered intravenously. Methods: Male ICR-CD1 mice were subjected to 15 -min suture MCAO under xylazine + ketamine anaesthesia. Na L-lactate $(2 \mu$ l of $100 \mathrm{mmol} / \mathrm{l}$ ) or vehicle was administered intracerebroventricularly at reperfusion. The neurological deficit was evaluated using a composite deficit score based on the neurological score, the rotarod test and the beam walking test. Mice were sacrificed at 14 days. In a second set of experiments, Na L-lactate $(1 \mu \mathrm{mol} / \mathrm{g}$ body weight) was administered intravenously into the tail vein at reperfusion. The neurological deficit and the lesion volume were measured at 48 h. Results: Intracerebroventricularly injected lactate induced sustained neuroprotection shown by smaller neuro-
\end{abstract}

logical deficits at 7 days (median $=0, \min =0, \max =3, \mathrm{n}=7$ vs. median $=2, \min =1, \max =4.5, n=5, p<0.05$ ) and 14 days after ischaemia (median $=0, \min =0, \max =3, n=7$ vs. median $=3, \min =0.5, \max =3, n=7, p=0.05$ ). Reduced tissue damage was demonstrated by attenuated hemispheric atrophy at 14 days $\left(1.3 \pm 4.0 \mathrm{~mm}^{3}, \mathrm{n}=7\right.$ vs. $12.1 \pm 3.8 \mathrm{~mm}^{3}, \mathrm{n}=$ $5, p<0.05)$ in lactate-treated animals. Systemic intravenous lactate administration was also neuroprotective and attenuated the deficit (median $=1, \min =0, \max =2.5, \mathrm{n}=12$ ) compared to vehicle treatment (median $=1.5, \min =1, \max =8$, $\mathrm{n}=12, \mathrm{p}<0.05)$ as well as the lesion volume at $48 \mathrm{~h}(13.7 \pm$ $12.2 \mathrm{~mm}^{3}, \mathrm{n}=12$ vs. $\left.29.6 \pm 25.4 \mathrm{~mm}^{3}, \mathrm{n}=12, \mathrm{p}<0.05\right)$. Conclusions: The beneficial effect of lactate is long-lasting: lactate protects the mouse brain against ischaemic damage when supplied intracerebroventricularly during reperfusion with behavioural and histological benefits persisting 2 weeks after ischaemia. Importantly, lactate also protects after systemic intravenous administration, a more suitable route of administration in a clinical emergency setting. These findings provide further steps to bring this physiological, commonly available and inexpensive neuroprotectant closer to clinical translation for stroke.

Copyright $\odot 2012$ S. Karger AG, Basel

\section{KARGER}

Fax +4161306 1234

E-Mail karger@karger.ch

www.karger.com (c) 2012 S. Karger AG, Basel

$1015-9770 / 12 / 0346-0329 \$ 38.00 / 0$

Accessible online at:

www.karger.com/ced
Lorenz Hirt, MD

Department of Clinical Neurosciences, Lausanne University Hospital BH 07-307, CHUV

$\mathrm{CH}-1011$ Lausanne (Switzerland)

E-Mail Lorenz.Hirt@chuv.ch 


\section{Introduction}

In the neurovascular unit, astrocytes line cerebral capillaries with their end feet and interact closely with neurons at the synapses. Brain activation is coupled to glucose uptake from the blood stream, which is likely to involve astrocytes due to the spatial organization of the neurovascular unit. Lactate, a product of anaerobic glycolysis, can be shuttled from astrocytes to neurons and used as an efficient energy substrate [1]. Lactate transport from astrocytes to neurons plays a physiological role as it was recently shown that this transport is critical for longterm memory [2]. Lactate shuttling also has an important role in physiopathological events $[3,4]$. Lactate protects neural tissue against excitotoxicity as it attenuates neuronal death induced by intracortical glutamate injection [3, 5]. Based on the knowledge of this beneficial role of lactate, we recently demonstrated that lactate could also prevent ischaemic neuronal death in vitro in hippocampal slice cultures subjected to oxygen and glucose deprivation [6] and in vivo, intracerebroventricular lactate injection after transient middle cerebral artery occlusion (MCAO) in mice attenuates both the lesion volume and the neurological deficit 2 days after ischaemia. We now show the effect of lactate neuroprotection on outcome at later time points as well as demonstrate a beneficial response at $48 \mathrm{~h}$ with intravenous administration. Lactate is a natural and easily available substance and our recent results are critical steps for its translation to clinical stroke patients.

\section{Materials and Methods}

\section{Transient MCAO in the Mouse}

All animal experiments were conducted according to Swiss guidelines for animal experimentation and approved by the veterinary authority. Male ICR-CD1 mice (body weight 26-35 g, Charles River, L'Arbresle, France) were anaesthetized by intraperitoneal injection of $8 \mathrm{mg} / \mathrm{kg}$ xylazine (Rompun $2 \%$, Bayer, Zurich, Switzerland) and $100 \mathrm{mg} / \mathrm{kg}$ ketamine (Ketanarkon 100, Streuli Pharma, Uznach, Switzerland). At $0 \mathrm{~h}$, ischaemia was induced by inserting a silicone-coated 8-0 filament (Doccol Corp., Redlands, Calif., USA) through the left common carotid artery into the internal carotid artery $[6,7]$. The filament was withdrawn after 15 min for reperfusion. Regional cerebral blood flow (rCBF) was measured by laser Doppler flowmetry (Periflux 5000, Perimed, Stockholm, Sweden) with a flexible probe fixed on the skull, $1 \mathrm{~mm}$ posteriorly and $6 \mathrm{~mm}$ laterally from the bregma and monitored throughout surgery. Rectal temperature was maintained at $37 \pm$ $0.5^{\circ} \mathrm{C}$ throughout surgery, using a temperature control unit (FHC, Bowdoinham, Me., USA). Mice were administered 0.025 $\mathrm{mg} / \mathrm{kg}$ of buprenorphine subcutaneously for analgesia after sur- gery. They were then housed overnight in an incubator at $31^{\circ} \mathrm{C}$. Mice were sacrificed after $48 \mathrm{~h}$ or 14 days. Among intracerebroventricularly injected mice, 5/18 died before the 14-day time point ( 2 died during surgery before treatment; 2 vehicle-treated mice died on day 4; 1 lactate-treated animal died on day 6). Among intravenously injected mice, $4 / 52$ died before $48 \mathrm{~h}$ ( 1 died during surgery before treatment; 3 vehicle-treated animals died on day 2).

\section{Lactate Treatment}

Two microlitres of either the $100 \mathrm{mmol} / \mathrm{l} \mathrm{Na}$ L-lactate (Fluka, Sigma-Aldrich, Buchs, Switzerland) solution corresponding to $200 \mathrm{mmol} / \mathrm{l}$ or vehicle $(1 \times \mathrm{PBS}, \mathrm{pH}$ 7.4) were randomly injected by a surgeon blinded to the treatment solution intracerebroventricularly at reperfusion into the left lateral ventricle $(0.9 \mathrm{~mm}$ laterally, $0.1 \mathrm{~mm}$ posteriorly, $3.1 \mathrm{~mm}$ deep from the bregma $[6,8])$ using a Hamilton syringe (Hamilton Company, Bonaduz, Switzerland).

Five microlitres per gram of body weight of $\mathrm{Na}$ L-lactate solution $(200 \mathrm{mmol} / \mathrm{l})$ or vehicle solution were injected by a surgeon blinded to the treatment solution intravenously (tail vein) administered at reperfusion using a $1-\mathrm{ml}$ syringe with a 25 -gauge needle and a mouse restrainer (Braintree Scientific Inc., Braintree, Mass., USA).

\section{Lesion Volume Measurement}

The lesion volume was calculated by multiplying the distance between sections by the lesion area, measured on $20-\mu \mathrm{m}$-thick cryostat sections stained with cresyl violet and by an examiner blinded to the treatment group. The hemispheric atrophy was calculated by subtracting the volume of the hemisphere which suffered ischaemic injury from the unaffected hemisphere.

\section{Immunohistochemistry}

Frozen cryostat brain sections were fixed with $4 \% p$-formaldehyde for $1 \mathrm{~h}$ at $4^{\circ} \mathrm{C}$, washed in $1 \times \mathrm{PBS}$ and incubated overnight at $4^{\circ} \mathrm{C}$ in $1 \times \mathrm{PBS}, 1 \%$ bovine serum albumin, and $0.1 \%$ Triton with neuronal nuclear antigen (NeuN) (Sigma) antibody (1:300 dilution). The sections were incubated for $1 \mathrm{~h}$ at room temperature in the same buffer with anti-mouse FITC (Jackson ImmunoResearch Laboratories, Baltimore, Md., USA) antibody. Sections were mounted in Vectashield (Vector Labs, Burlingame, Calif., USA). Images were acquired with the Axiovision v4.8 software using a Zeiss Axiovision microscope (488 nm absorbance).

\section{Behavioural Evaluation}

A composite neuroscore [6, 9] was used to assess the neurological deficit, as previously described [6]. The composite score is based on three tests, each with a maximum of 3 points: the neuroscore $(0=$ no observable neurologic deficit; $1=$ failure to extend the right forepaw; 2 = circling to the contralateral side, and $3=$ loss of walking or righting reflex); secondly, the beam walking test [10] $(0=$ the mouse walks directly to the end of the beam; $1=$ the mouse walks along the beam with a few slips; $2=$ the mouse cannot walk more than a few steps, and $3=$ the mouse does not move); finally, the rotarod treadmill (UgoBasile, Comerio, Italy) test [10], i.e. the mice are placed on a rotating drum, set to accelerate uniformly from 4 to $40 \mathrm{rpm}$, and their latency to fall from it is recorded. Animals were trained 3 times over the 2 days before sur- 
gery, with 2 trials for each session. The test was then performed at different time points after $\mathrm{MCAO}$, and the better of the 2 consecutive trials was selected. Points were attributed on the basis of performance expressed as a percentage of the best performance before ischaemia (0 point: $90-100 \%$ and then 0.5 point for each $15 \%$ decrease) [6].

\section{Exclusion Criteria}

The surgeon applied strict exclusion criteria before statistical analysis: mice with temperature outside the $36.5-37.5^{\circ} \mathrm{C}$ limit, an rCBF above $20 \%$ of baseline during ischaemia or below $50 \%, 10$ min after reperfusion. In intravenously injected mice, those mice for which the surgeon doubted the quality of injection were excluded. In total, 1 mouse out of 13 was excluded from the intracerebroventricular group and 24/48 from the intravenous group.

\section{Brain Lactate Measurements}

Mice underwent cerebral ischaemia followed by lactate or vehicle injection (intravenous or intracerebroventricular). Thirty minutes after injection, animals were sacrificed by intracardiac PBS perfusion for $2 \mathrm{~min}$ to remove blood. Brains were isolated and frozen in liquid nitrogen vapour.

Brain lactate was measured in each hemisphere by an enzymatic-spectrometric protocol in which lactate contained in the sample is incubated with lactate dehydrogenase $(14 \mathrm{U} / \mathrm{ml})$ and $3 \mathrm{mmol} / \mathrm{l} \mathrm{NAD}$ in glycine-semicarbazide $0.2 \mathrm{~mol} / \mathrm{l}$ buffer, $\mathrm{pH} 10$. $\mathrm{NADH}$ resulting from the reaction is measured by its absorbance at $340 \mathrm{~nm}[11,12]$.

\section{Blood Gas Analysis}

Mice were injected intravenously with either lactate or PBS. Arterial blood $(125 \mu \mathrm{l})$ was withdrawn from the carotid artery 15-26 min after injection and collected in Clinitubes (Radiometer, Denmark). Samples were analysed for blood gases and lactate in a Radiometer ABL800 Flex machine.

\section{Statistics}

Parametric data were presented as mean \pm standard deviation and scores as median, minimum, maximum. Statistical analyses were carried out using the non-parametric two-tailed MannWhitney test (Instat, Graphpad, La Jolla, Calif., USA). A probability of 0.05 or less was considered significant.

\section{Results}

\section{Intracerebroventricular Injection of Lactate}

Attenuates Ischaemia-Induced Hemispheric Atrophy and Improves the Functional Outcome 14 Days after Transient MCAO in Mice

To extend our previous observation of neuroprotection with intracerebroventricular injection of lactate after mouse MCAO, we subjected mice to 15 min transient MCAO under xylazine + ketamine anaesthesia. In this model, the striatal and small cortical lesions seen at early time points were even smaller at 14 days in both groups. Therefore, lactate treatment did not appear to induce a significant reduction in lesion size at this late time point $\left(5 \pm 3 \mathrm{~mm}^{3}, \mathrm{n}=7\right.$ vs. $8 \pm 3 \mathrm{~mm}^{3}$ in vehicle treatment, $\mathrm{n}=5, \mathrm{p}=0.17$ ) (fig. 1a). Although the small size of lesions may have a confounding effect, reduced tissue damage in lactate-treated mice was demonstrated indirectly by attenuated hemispheric atrophy $\left(1 \pm 4 \mathrm{~mm}^{3}, \mathrm{n}=7\right.$, vs. 12 $\pm 4 \mathrm{~mm}^{3}, \mathrm{n}=5, \mathrm{p}=0.048$ ) (fig. $\mathrm{lb}$ ). Very convincing results were obtained by looking at the neurological impairment detected by an increase in the composite behavioural outcome score, peaking at 2 days and with partial recovery at 7 and 14 days after MCAO. Lactate treatment induced a sustained neuroprotection attested by smaller neurological deficits at 2 days (median neuroscore $=1.5$, $\min =1, \max =3.5, \mathrm{n}=6$ vs. median $=4.75, \min =1.5$, $\max =7.0, \mathrm{n}=6$ in vehicle-treated animals, $\mathrm{p}=0.036), 7$ days (median $=0, \min =0, \max =3, \mathrm{n}=7$ vs. median $=$ $2, \min =1, \max =4.5, \mathrm{n}=5, \mathrm{p}=0.028)$ and 14 days after ischaemia (median $=0, \min =0, \max =3, \mathrm{n}=7$ vs. me$\operatorname{dian}=3, \min =0.5, \max =3, \mathrm{n}=7, \mathrm{p}=0.05)$ (fig. 1c). To evaluate delayed neuronal loss, we performed immunohistochemistry with an antibody against $\mathrm{NeuN}$ in brain slices from mice 14 days after $15 \mathrm{~min} \mathrm{MCAO}$ and injected with either PBS (fig. 1d) or lactate (fig. 1e). The ischaemic lesion corresponds to a region of reduced intensity of NeuN staining compared to the contralateral hemisphere in both treatment groups, demonstrating neuronal loss at this delayed time point.

There was no difference in temperature, body weight and $\mathrm{rCBF}$ during surgery and reperfusion between the groups.

\section{Lactate Injected Intravenously at Reperfusion}

Attenuates both the Lesion Volume and Neurological Deficit $48 \mathrm{~h}$ after Transient MCAO in Mice

Early treatment to halt the progression of ischaemic damage is very important in acute stroke, hence the importance of a practical and quick route of administration for a medication. We therefore tested intravenous injection of lactate into the tail vein at reperfusion. In healthy human brains, lactate injected intravenously (0.75-3 $\mu \mathrm{mol} / \mathrm{g}$ ) was shown to be metabolized. Lactate administered intravenously was also shown to protect the human brain against intracranial hypertensive episodes in severe traumatic brain injury [13-15]. We tested doses of 1 and $3 \mu \mathrm{mol} / \mathrm{g}$ in a preliminary experiment (injection of $3 \mu \mathrm{mol} / \mathrm{g}$ was toxic and led to the death of 2 mice tested). We compared the concentration of lactate in the target organ, the brain, with intracerebroventricular and intravenous $(1 \mu \mathrm{mol} / \mathrm{g})$ injections and showed that tail vein lactate injection after reperfusion was able to increase 

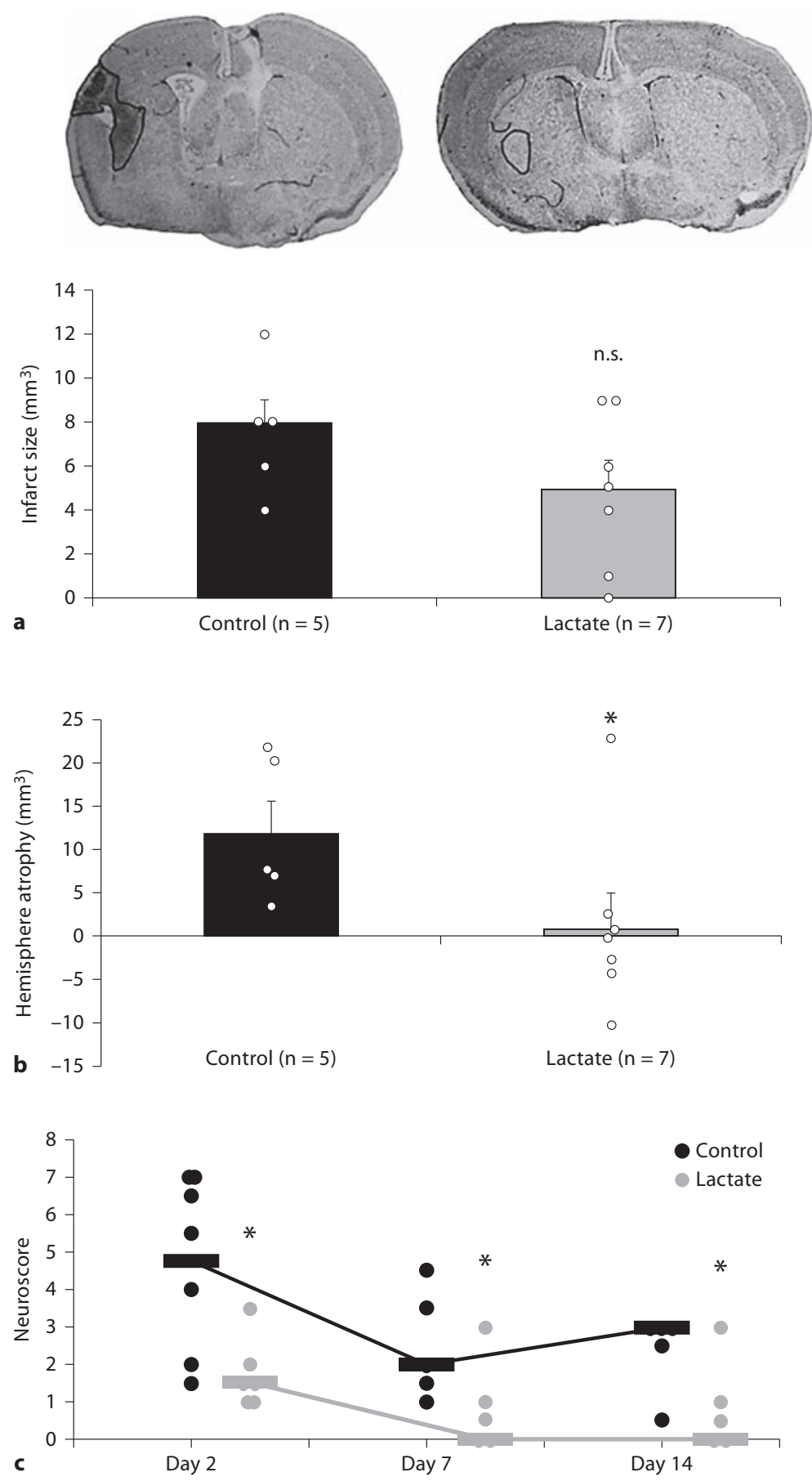
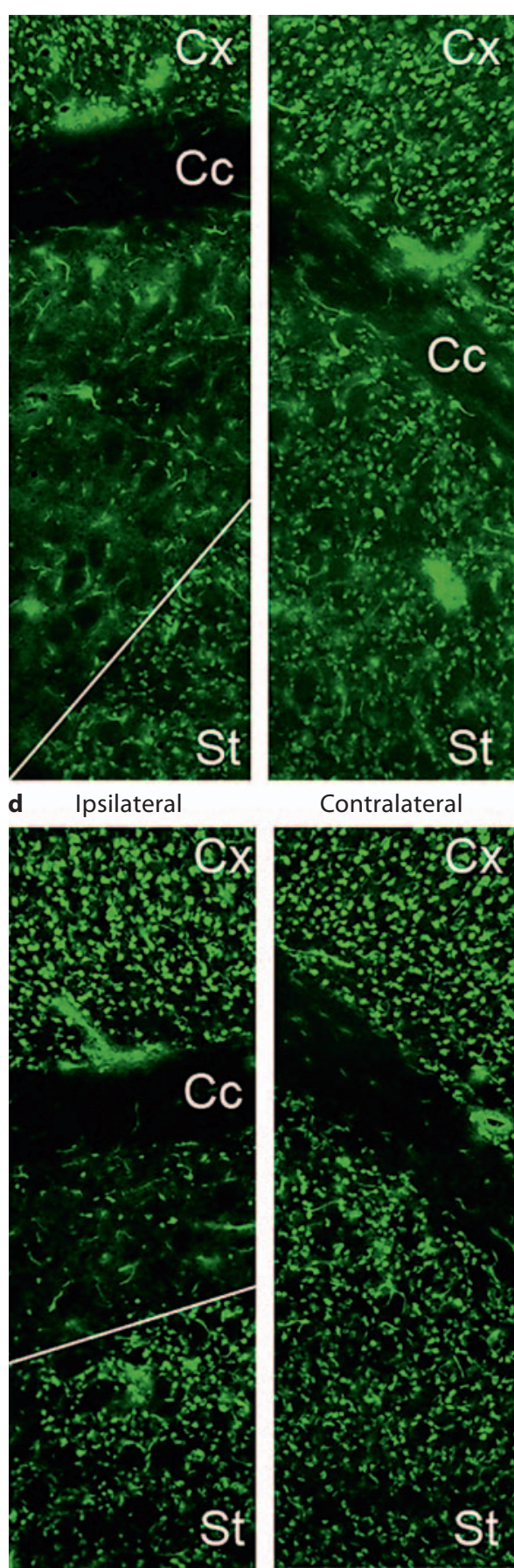

e Ipsilateral
Contralateral

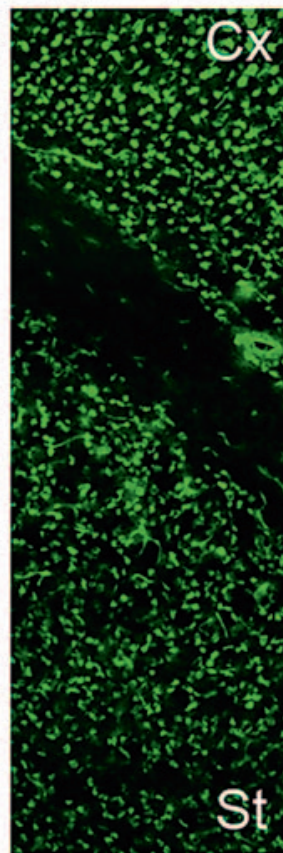

Contralateral
Fig. 1. Intracerebroventricular injection of $200 \mathrm{mmol} / \mathrm{l}$ lactate induces sustained neuroprotection after 15-min MCAO. a Infarct size measured at 14 days after MCAO represented as mean \pm SD. b Atrophy of the injured hemisphere measured at 14 days after MCAO represented as mean \pm SD. c Evolution of neurologic deficit scores (from $0=$ no deficit, to $9=$ most severe deficit) up to 14 days after MCAO, represented as medians. d, e Immunohistochemistry with an antibody against $\mathrm{NeuN}$ was performed on brain slices from mice 14 days after 15-min MCAO and injected with either PBS (d) or lactate (e). The ischaemic lesion, outlined in white, corresponds to a region of reduced intensity of NeuN staining compared to the contralateral hemisphere in both treatment groups. ${ }^{*} \mathrm{p} \leq 0.05$ for the Mann-Whitney test, two-tailed $\mathrm{p}$ value. Circles represent individual animals. $\mathrm{Cx}=\mathrm{Cortex}$; $\mathrm{Cc}=$ corpus callosum; $\mathrm{St}=$ striatum. 
Fig. 2. Brain lactate concentration is similar after intravenous (i.v.) injection of $1 \mu \mathrm{mol} / \mathrm{g}$ lactate or intracerebroventricular (i.c.v.) injection of $2 \mu \mathrm{l}$ of $100 \mathrm{mmol} / \mathrm{l}$ lactate. Lactate concentration was measured in the ischaemic hemisphere $30 \mathrm{~min}$ after lactate injection.

Fig. 3. Intravenous injection of $1 \mu \mathrm{mol} / \mathrm{l}$ lactate/g body weight at reperfusion after 15-min MCAO is neuroprotective. a Infarct size measured at $48 \mathrm{~h}$ after MCAO represented as mean \pm SD. b Neurologic deficit scores (from $0=$ no deficit, to $9=$ most severe deficit) at $48 \mathrm{~h}$ after MCAO, represented as medians. ${ }^{*} \mathrm{p} \leq 0.05$ for the Mann-Whitney test, two-tailed $\mathrm{p}$ value. Circles represent individual animals.
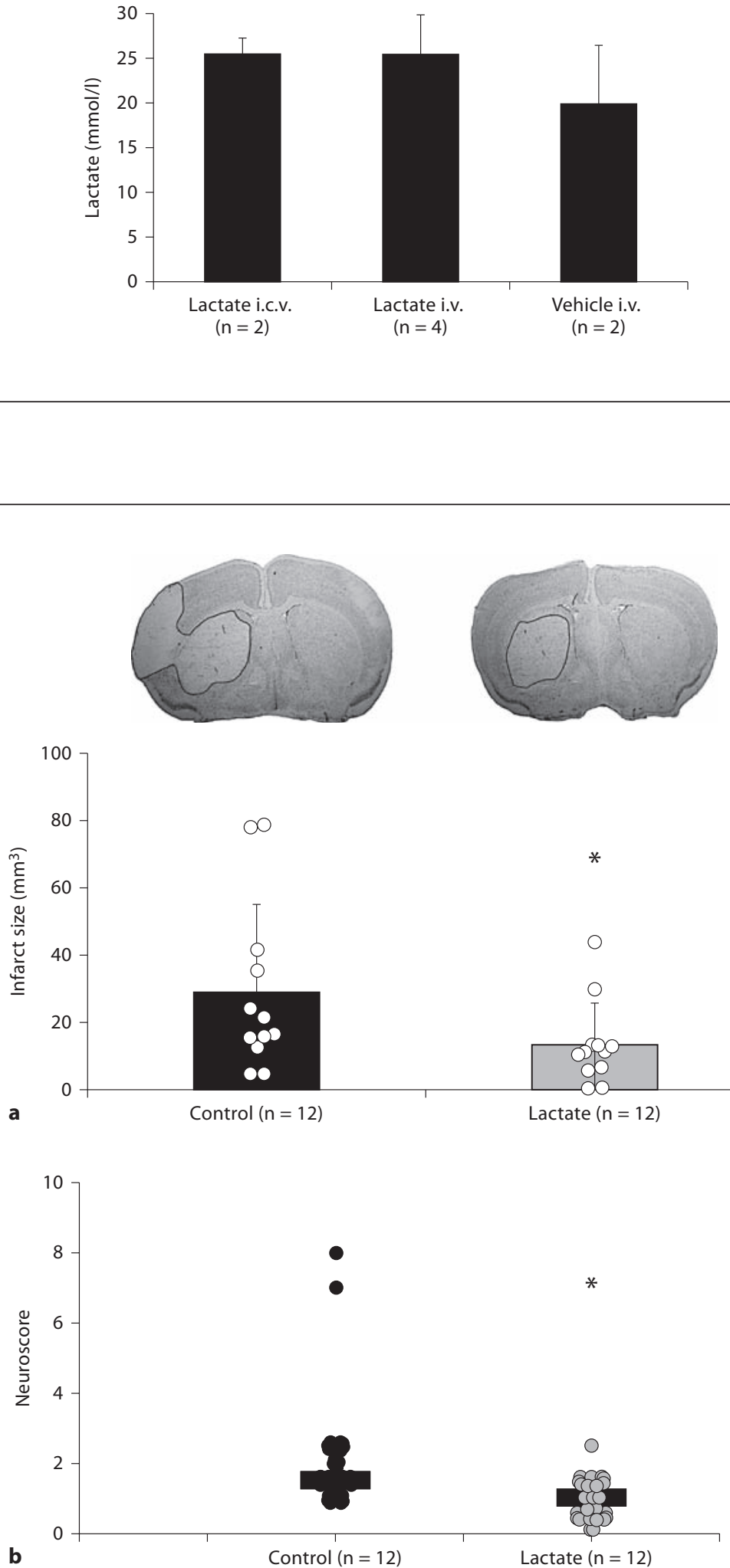
the brain lactate concentration to a comparable level (after $30 \mathrm{~min}$ ) as an intracerebroventricular injection of $2 \mu \mathrm{l} 100 \mathrm{~mm}$ lactate, recently shown to be neuroprotective [6] (fig. 2). Experiments were done with a dose of $5 \mu \mathrm{l}$ of $200 \mathrm{mmol} / \mathrm{l} \mathrm{L}$-lactate solution per gram of body weight, corresponding to $1 \mu \mathrm{mol} / \mathrm{g}$ of body weight. Controls received an equal volume of vehicle solution. Lactate administered intravenously attenuated the lesion volume $\left(13.7 \pm 12.2 \mathrm{~mm}^{3}, \mathrm{n}=12\right.$ vs. $29.6 \pm 25.4 \mathrm{~mm}^{3}$, $\mathrm{n}=12, \mathrm{p}=0.046)$ as well as, importantly, the neurological deficit $($ median $=1, \min =0, \max =2.5, \mathrm{n}=12)$ compared to vehicle treatment $($ median $=1.5, \min =1$, $\max =8, \mathrm{n}=12, \mathrm{p}=0.024$ ) at $48 \mathrm{~h}$ (fig. 3). These results show that a very practical intravenous administration of lactate induces neuroprotection.

There was no difference in the temperature, body weight and $\mathrm{rCBF}$ during surgery and reperfusion between the groups. Similarly, the $\mathrm{pH}, \mathrm{pCO}_{2}, \mathrm{pO}_{2}$ and lactate measured in the arterial blood after intravenous injection were not different between the groups (data not shown).

\section{Discussion}

In this paper, we show that the neuroprotective effect of lactate, now tested in a 15-min MCAO under xylazine-ketamine anaesthesia, extends beyond $48 \mathrm{~h}$, with improvement in the behavioural outcome and attenuated tissue destruction with significantly less hemisphere atrophy at 14 days. It is important to determine if neuroprotection is long-lasting as long-term neurological outcome is clinically more relevant than shortterm outcome, attested by the NINDS recombinant tissue plasminogen activator study [16] and the more recent ECASS 3 [17] trial, both of which used the behavioural outcome at 3 months as a primary outcome measure.

Cerebral ischaemia causes rapidly progressing and devastating tissue damage in the ischaemia territory. An early intervention is of critical importance to impede the lesion progression. This is why we needed to establish a clinically more feasible route of administration than injection into the brain. We chose intravenous administration as it is reliable and practical in the case of stroke patients. The results presented here support the ability of intravenously injected lactate to cross the blood-brain barrier $[13,14]$ and efficiently protect the brain as was also seen in traumatic brain injury patients, a very different injury model [15]. However, its mode of action re- mains unclear. Indeed, in the case of ischaemia, lactate is known to increase in the brain in two waves: a first increase during ischaemia due to anaerobic glycolysis and a second increase beginning $1 \mathrm{~h}$ after reperfusion and continuing up to $72 \mathrm{~h}$ [18-20]. Lactate levels in the brain are thus very high during ischaemia and after reperfusion and consequently the addition of a small amount of lactate may appear pointless. However, a careful look at the lactate kinetics shows that between $15 \mathrm{~min}$ and $1 \mathrm{~h}$ after reperfusion, lactate concentrations are back to normal and it is exactly at this time point that we inject lactate. At reperfusion, there is a huge energy demand, which cannot be met by glucose as ATP stores are depleted and glucose cannot be converted to glucose-6P for glycolysis. In these conditions, lactate accumulated during ischaemia by anaerobic glycolysis represents an ideal source of energy, which can explain the rapid decrease of the accumulated lactate and return to baseline in the first hour of reperfusion and the beneficial effect of additional lactate supply at this time point.

The second increase in lactate is not due to anaerobic glycolysis as it occurs after reperfusion with restored oxygen supply and may be explained by the astrocyte-neuron shuttle model [1]. Astrocytes are more resistant to ischaemia than neurons. When neurons are dying, the lactate produced by surviving astrocytes cannot be consumed by neurons, hence an increase in lactate. Lactate production could also reflect an attempt of the ischaemic brain to rescue its suffering neurons. In less severe ischaemia, the second lactate increase occurs later, coinciding with a more delayed neuronal demise [21]. Similarly, locating where the lactate increase occurs in the brain using spatial mapping by magnetic resonance spectroscopy $24 \mathrm{~h}$ after ischaemia shows a gradient with highest lactate concentrations in the centre of the ischaemic lesion correlating with the severity of tissue damage [19].

Another mode of action of lactate shown in traumatic brain injury is an attenuation of cellular swelling [15]. The proposed explanation for this observation is that the injected lactate solution contains both metabolizable (lactate) and non-metabolizable ( $\mathrm{Na}$ ) ions. The use of lactate by brain cells induces an imbalance between positive and negative charges which needs to be compensated by an efflux of anions from cells, accompanied by water, thus counteracting the detrimental cellular swelling [15].

Recent exciting results on the role of oligodendrocytes in enhancing axon function and neuronal survival in models of amyotrophic lateral sclerosis also point towards a role for lactate. There is a metabolic interaction 
between oligodendroglia and neurons with lactate transport from oligodendroglia to neurons [22].

In conclusion, although some aspects of its role as a neuroprotectant remain intriguing, lactate is an exciting candidate for neuroprotection in ischaemic stroke. The results presented here bring this natural and inexpensive agent closer to a translation to stroke patients.

\section{Acknowledgments}

We thank Dr. Melanie Price for critically reading the manuscript and helpful suggestions, Dr. Mauro Oddo for the helpful discussion, Valery Plouhinec for the technical help with the blood gas analysis machine and Dr. Lara Buscemi for helping with the illustrations. This work was supported by a grant from the Gianni Biaggi de Blasys Foundation.

\section{Disclosure Statement}

The authors report no conflict of interest with this work.

\section{References}

1 Pellerin L, Magistretti PJ: Glutamate uptake into astrocytes stimulates aerobic glycolysis: a mechanism coupling neuronal activity to glucose utilization. Proc Natl Acad Sci USA 1994;91:10625-10629.

-2 Suzuki A, Stern SA, Bozdagi O, Huntley GW, Walker RH, Magistretti PJ, Alberini CM: Astrocyte-neuron lactate transport is required for long-term memory formation. Cell 2011; 144:810-823.

-3 Schurr A, Payne RS, Miller JJ, Rigor BM: Brain lactate is an obligatory aerobic energy substrate for functional recovery after hypoxia: further in vitro validation. J Neurochem 1997;69:423-426.

4 Schurr A, Payne RS, Miller JJ, Rigor BM: Brain lactate, not glucose, fuels the recovery of synaptic function from hypoxia upon reoxygenation: an in vitro study. Brain Res 1997;744:105-111.

5 Ros J, Pecinska N, Alessandri B, Landolt H, Fillenz M: Lactate reduces glutamate-induced neurotoxicity in rat cortex. J Neurosci Res 2001;66:790-794.

-6 Berthet C, Lei H, Thevenet J, Gruetter R, Magistretti PJ, Hirt L: Neuroprotective role of lactate after cerebral ischemia. J Cereb Blood Flow Metab 2009;29:1780-1789.

7 Benakis C, Bonny C, Hirt L: JNK inhibition and inflammation after cerebral ischemia. Brain Behav Immun 2010;24:800-811.

-8 Granziera C, Thevenet J, Price M, Wiegler K, Magistretti PJ, Badaut J, Hirt L: Thrombininduced ischemic tolerance is prevented by inhibiting c-Jun N-terminal kinase. Brain Res 2007;1148:217-225.
9 Michel-Monigadon D, Bonny C, Hirt L: cJun N-terminal kinase pathway inhibition in intracerebral hemorrhage. Cerebrovasc Dis 2010;29:564-570.

10 Carter RJ, Morton J, Dunnett SB: Motor coordination and balance in rodents. Curr Protoc Neurosci 2001;8:8.12.

11 Allaman I, Pellerin L, Magistretti PJ: Glucocorticoids modulate neurotransmitter-induced glycogen metabolism in cultured cortical astrocytes. J Neurochem 2004;88:900908.

12 Rosenberg JC, Rush BF: An enzymatic-spectrophotometric determination of pyruvic and lactic acid in blood. Methodologic aspects. Clin Chem 1966;12:299-307.

13 Smith D, Pernet A, Hallett WA, Bingham E, Marsden PK, Amiel SA: Lactate: A preferred fuel for human brain metabolism in vivo. J Cereb Blood Flow Metab 2003;23:658-664.

14 Qu H, Haberg A, Haraldseth O, Unsgard G, Sonnewald U: (13)C MR spectroscopy study of lactate as substrate for rat brain. Dev Neurosci 2000;22:429-436.

15 Ichai C, Armando G, Orban JC, Berthier F, Rami L, Samat-Long C, Grimaud D, Leverve $\mathrm{X}$ : Sodium lactate versus mannitol in the treatment of intracranial hypertensive episodes in severe traumatic brain-injured patients. Intensive Care Med 2009;35:471479.

16 The National Institute of Neurological Disorders and Stroke rt-PA Stroke Study Group: Tissue plasminogen activator for acute ischemic stroke. N Engl J Med 1995;333:15811587.
17 Hacke W, Kaste M, Bluhmki E, Brozman M, Davalos A, Guidetti D, Larrue V, Lees KR, Medeghri Z, Machnig T, Schneider D, von KR, Wahlgren N, Toni D: Thrombolysis with alteplase 3 to 4.5 hours after acute ischemic stroke. N Engl J Med 2008;359:1317-1329.

18 Higuchi T, Fernandez EJ, Maudsley AA, Shimizu H, Weiner MW, Weinstein PR: Mapping of lactate and $\mathrm{N}$-acetyl-L-aspartate predicts infarction during acute focal ischemia: in vivo $1 \mathrm{~h}$ magnetic resonance spectroscopy in rats. Neurosurgery 1996;38:121-129; discussion 129-130.

19 Alf MF, Lei H, Berthet C, Hirt L, Gruetter R, Mlynarik V: High-resolution spatial mapping of changes in the neurochemical profile after focal ischemia in mice. NMR Biomed 2012;25:247-254.

20 Lei H, Berthet C, Hirt L, Gruetter R: Evolution of the neurochemical profile after transient focal cerebral ischemia in the mouse brain. J Cereb Blood Flow Metab 2009;29: 811-819.

21 Berthet C, Lei H, Gruetter R, Hirt L: Early predictive biomarkers for lesion after transient cerebral ischemia. Stroke 2011;42:799805 .

22 Lee Y, Morrison BM, Li Y, Lengacher S, Farah MH, Hoffman PN, Liu Y, Tsingalia A, Jin L, Zhang PW, Pellerin L, Magistretti PJ, Rothstein JD: Oligodendroglia metabolically support axons and contribute to neurodegeneration. Nature 2012;487:443-448. 